Bioaccumulation of Polycyclic Aromatic Hydrocarbons in Gilthead Sea Bream (Sparus aurata L.) Exposed to Long Term Feeding Trials with Different Experimental Diets.

J. Nácher-Mestre, R. Serrano, L. Benedito-Palos, J. C. Navarro, F. J. López, S. Kaushik, J. Pérez-Sánchez

Archives of Environmental Contamination and Toxicology 59 (2010) 137-146 



\title{
Bioaccumulation of Polycyclic Aromatic Hydrocarbons in Gilthead Sea Bream (Sparus aurata L.) Exposed to Long Term Feeding Trials with Different Experimental Diets
}

\author{
Jaime Nácher-Mestre • Roque Serrano • Laura Benedito-Palos • \\ Juan C. Navarro · Francisco J. López • Sadasivam Kaushik • \\ Jaume Pérez-Sánchez
}

Received: 8 September 2009/ Accepted: 7 December 2009/Published online: 27 December 2009

(C) Springer Science+Business Media, LLC 2009

\begin{abstract}
Polycyclic aromatic hydrocarbons (16 EPA list) were determined in oils, fish feed, and fillets from gilthead sea bream fed through a full production cycle (14 months) with feed containing different proportions of fish oil replaced by vegetable oils, followed by a finishing phase with fish oil. At the beginning of the study, fish presented $46.6 \mu \mathrm{g} / \mathrm{kg}$ fresh weight of the sum of PAHs in fillet and a benzo[a]pyrene equivalent value of $9.1 \mu \mathrm{g} / \mathrm{kg}$ fresh weight. These levels decreased after 330 days of rearing to values around $2 \mu \mathrm{g} / \mathrm{kg}$. Although the concentration increased again during the finishing phase, they remained low. These low concentrations of PAHs could be the result of a dilution process associated with fish growth and with the detoxification pathways, both favored by the low levels of PAHs present in the feeds and the lack of any other potential source of contamination during the whole rearing period.
\end{abstract}

Polycyclic aromatic hydrocarbons (PAHs) are compounds formed by two or more fused aromatic rings originating from natural and anthropogenic sources, such as incomplete combustions, industrial incinerations, transport, or uncontrolled spills. Sixteen of them have been included in the list of priority pollutants by the US Environmental Protection Agency (EPA) as a consequence of their potential adverse effects on organisms, including human health (EPA 1987). Over recent years, a concern has arisen about the impact of these contaminants in coastal environments and on human 
consumers, especially as a consequence of accidental spills (Cortazar et al. 2008). They are ubiquitous in the marine environment, and due to their hydrophobic nature, they tend to be absorbed rapidly on suspended materials and sediment, becoming bioavailable to fish and other marine organisms through the food chain (Latimer and Zheng 2003; Liang et al. 2007; Perugini et al. 2007).

Polycyclic aromatic hydrocarbons are carcinogenic in mammalian species and in some fish species (Hendricks et al. 1985; Schultz and Schultz 1982). Many chemical carcinogens are procarcinogens requiring biotransformation frequently by oxidative metabolism through the cytochrome P-450 monooxygenase system (Stegeman and Lech 1991). Metabolization and depuration ability of PAHs by fish has been investigated and stated by several authors (Ferreira et al. 2006; Kennedy et al. 2004; Martin-Skilton et al. 2008).

Marine aquaculture has seen strong development in the last few decades in order to meet the increased fish consumption by the world population and the decreasing wild stocks. In populations having high seafood consumption, both farmed and wild seafood products can also contribute toward contaminant load of the food basket (Martí-Cid et al. 2007, 2008). Fish used as raw material for the manufacture of fish oil (FO) and fish meal as feed ingredients are a possible source of PAHs in fish feed that could possibly be bioaccumulated by farmed fish (Hellou et al. 2005). Likewise, vegetable oils used in fish feed manufacture are another possible source of PAHs (Moret and Conte 2000). Aquaculture products are subject to increasing strict control and regulation. The European Commission Regulation (EC) 1881/2006 of December 2006 has fixed maximum levels of 2 $\mu \mathrm{g} / \mathrm{kg}$ fresh weight for benzo[a]pyrene (BaPy) in fish. Additionally, some countries have adopted a legal limit of $1 \mu \mathrm{g} / \mathrm{kg}$ for BaPy content in smoked fish foodstuff (Bories 1988). However, there appear to be no legal limits for vegetable oils (Moret and Conte 2000).

In order to estimate the toxicity of PAHs, it is common to apply toxic equivalent factors (TEFs) for each individual congener in comparison with the carcinogenic activity of BaPy. For comparative purposes, the PAH concentrations are summed and also expressed as benzo[a]pyrene equivalents (BaPEs), their relative concentrations being weighted in relation to the carcinogenic potential of individual PAH compounds using equivalency factors (Law et al. 2002). The BaPEs values calculated represent the toxicity of the charge load of PAHs in each sample (EPA 2000; Nisbet and LaGoy 1992).

A wide variety of environmental pollutants have been detected in farmed fish (Bordajandi et al. 2006; Easton et al. 2002; Hites et al. 2004; Liang et al. 2007; Maule et al. 2007; Perugini et al. 2007; Santerre et al. 2000; Serrano et al. 2008a, 2008b). Fish meal and FO commonly used as feed ingredients, especially from the northern hemisphere, are known to contain persistent organic 
pollutants (POPs) at different levels and a reduction of these POPs is an issue of concern (Oterhals and Nygård 2008; Oterhals et al. 2007).

The use of plant-based ingredients as alternatives to fish meal and FO can potentially reduce the charge load of lipophilic contaminants in aquafeeds, and thereby in farmed fish, improving at the same time the sustainability of marine fishery resources (Bell et al. 2005; Berntssen et al. 2005; Bethune et al. 2006). Although the presence and accumulation of organochlorine compounds in farmed fish have been studied rather extensively (Bordajandi et al. 2006; Easton et al. 2002; Hites et al. 2004; Jacobs et al. 1998; Santerre et al. 2000; Serrano et al. 2008a, 2008b), very little information is available on the behavior of PAHs in the aquaculture food chain, apart from guidances on risk assessment for animal and humans (Commission Regulation 2006; EPA 1993, 2000).

This work is part of a broader study aiming at analyzing the effects of FO substitution by vegetable oils in low-fish-meal diets. Whereas other parts of the study have dealt with fatty acid metabolism (Benedito-Palos et al. 2009) and the bioaccumulation of organochlorine compounds (Nácher-Mestre et al. 2009a), the main objective of the present study was to follow the potential accumulation of PAHs in fast-growing juveniles of the gilthead sea bream (Sparus aurata L.), a major farmed fish in the Mediterranean aquaculture, exposed through the entire productive cycle to feeds with graded levels of FO replaced by a mixture of vegetable oils and then switched for 3 months to a finishing feed based on FO. The levels of PAHs and their equivalence as BaPEs were determined in oils, feeds, and fish fillets in order to gather information on the effects of dietary oil sources on endproduct quality and safety.

\section{Materials and Methods}

Experimental Diets

Three (isoproteic, isolipidic, and isoenergetic) feeds were formulated with a low inclusion level (20\%) of fish meal and fish soluble protein concentrates. Fish oil from the southern hemisphere was the only lipid source in the control diet (FO), which was also used during the finishing period. The two remaining diets contained a blend of vegetable oils ( 2.5 rapeseed oil: 8.8 linseed oil: 3 palm oil), replacing $33 \%(33 \mathrm{VO})$ and $66 \%$ (66VO) of the FO. All diets were manufactured using a twin-screw extruder (Clextral, BC 45) at the Institut National de la Recherche Agronomique (INRA) experimental research station of Donzacq (Landes, France), dried under hot air, sealed, and kept in air-tight bags until use. Ingredients and approximate composition of the feeds are reported in Table 1. 
Bioaccumulation Experiment

Gilthead sea bream obtained from Ferme Marine de Douhet, Ile d'Oléron, France were acclimatized at the Instituto de Acuicultura de Torre de la Sal (IATS) for 20 days before the start of the study. Fish of $\sim 18 \mathrm{~g}$ initial mean body weights were allocated into 9 fiberglass tanks (3000 L) in groups of 150 fish per tank. Water flow was $20 \mathrm{~L} / \mathrm{min}$ and the oxygen content of outlet water remained above $85 \%$ saturation. The growth study was undertaken over 14 months (July 11, 2006 to September 2, 2007). The photoperiod and water temperature $\left(10-26^{\circ} \mathrm{C}\right)$ varied over the course of the trial following natural changes at IATS latitude $\left(40^{\circ} 5^{\prime} \mathrm{N} ; 0^{\circ} 10^{\prime} \mathrm{E}\right)$.

During the first 11 months of the trial, the three diets were randomly allocated to triplicate groups of fish and feed was offered by hand to apparent visual satiety. During the finishing feeding phase (12 weeks, June 6, 2007 to September 2, 2007), two tanks of the 33VO and two of the 66VO groups were fed with the FO diet. These groups were then renamed 33VO/FO and 66VO/FO, respectively. Fish fed the FO diet and one tank each of fish fed $33 \mathrm{VO}$ and $66 \mathrm{VO}$ diets were maintained on the initial diets until the end of the study. This led to five treatments in the bioaccumulation study: FO, 33VO, 66VO, 33VO/FO, and 66VO/FO (Fig. 1).

At the beginning and at regular intervals throughout the finishing feeding phase $(0,330,360$, 390, and 420 days), randomly selected fish (eight per treatment) were killed by a blow on the head prior to tissue sampling, and the left-side fillet (with skin and bone removed) was excised and stored at $-20^{\circ} \mathrm{C}$ until analysis. Body weight and fillet yield were not affected by the dietary treatments over the course of the feeding trial (Benedito-Palos et al. 2009). Seawater for fish culture was checked using the methodology for PAHs described by Pitarch et al. (2007) and no PAH was detected (limit of detection: 5 and $100 \mathrm{ng} / \mathrm{L}$ ), thus ensuring that no known PAH exposure other than that from feeds was expected during the study.

\section{Analytical Method}

Polycyclic aromatic hydrocarbons included in the list of priority contaminants by the US EPA (EPA 1987) were analyzed in oils, fish feed, and fish fillets following the method described by NácherMestre et al. (2009b). Samples were collected and stored at $-20^{\circ} \mathrm{C}$ until analysis. Eight fish from each 
Table 1. Ingredients and chemical composition of experimental diets.

\begin{tabular}{|c|c|c|c|}
\hline & FO & $33 v o$ & $66 \mathrm{VO}$ \\
\hline \multicolumn{4}{|l|}{ Ingredient (\%) } \\
\hline Fish meal $(C P 70 \%)^{a}$ & 15 & 15 & 15 \\
\hline CPSP $90^{b}$ & 5 & 5 & 5 \\
\hline Corn gluten & 40 & 40 & 40 \\
\hline Soybean meal & 14.3 & 14.3 & 14.3 \\
\hline Extruded wheat & 4 & 4 & 4 \\
\hline Fish oil $^{c}$ & 15.15 & 10.15 & 5.15 \\
\hline Rapeseed oil & 0 & 0.85 & 1.7 \\
\hline Linseed oil & 0 & 2.9 & 5.8 \\
\hline Palm oil & 0 & 1.25 & 2.5 \\
\hline Soya lecithin & 1 & 1 & 1 \\
\hline Binder & 1 & 1 & 1 \\
\hline Mineral premix ${ }^{d}$ & 1 & 1 & 1 \\
\hline Vitamin premix $^{\mathrm{e}}$ & 1 & 1 & 1 \\
\hline $\mathrm{CaHPO}_{4} \cdot 2 \mathrm{H}_{2} \mathrm{O}(18 \% \mathrm{P})$ & 2 & 2 & 2 \\
\hline L-Lysine & 0.55 & 0.55 & 0.55 \\
\hline \multicolumn{4}{|l|}{ Composition } \\
\hline Dry matter (DM \%) & 93.13 & 92.9 & 92.77 \\
\hline Protein (\% DM) & 53.2 & 52.81 & 52.62 \\
\hline Fat (\% DM) & 21.09 & 21 & 20.99 \\
\hline Ash (\% DM) & 6.52 & 6.69 & 6.57 \\
\hline
\end{tabular}

\footnotetext{
${ }^{a}$ Fish meal (Scandinavian LT)

${ }^{b}$ Fish soluble protein concentrate (Sopropêche, France)

${ }^{\mathrm{c}}$ Fish oil (Sopropêche, France)

${ }^{\mathrm{d}}$ Supplied the following (mg $\cdot \mathrm{kg} / \mathrm{diet}$, except as noted): calcium carbonate $(40 \% \mathrm{Ca}) 2.15 \mathrm{~g}$, magnesium hydroxide $(60 \% \mathrm{Mg}) 1.24 \mathrm{~g}$, potassium chloride $0.9 \mathrm{~g}$, ferric citrate $0.2 \mathrm{~g}$, potassium iodine $4 \mathrm{mg}$, sodium chloride $0.4 \mathrm{~g}$, calcium hydrogen phosphate $50 \mathrm{~g}$, copper sulphate 0.3 , zinc sulphate 40 , cobalt sulphate 2 , manganese sulphate 30 , sodium selenite 0.3 .

${ }^{\text {e}}$ Supplied the following $(\mathrm{mg} \cdot \mathrm{kg} / \mathrm{diet}$ ): retinyl acetate 2.58; DL-cholecalciferol, 0.037; DL- $\alpha$ tocopheryl acetate, 30; menadione sodium bisulphite, 2.5; thiamin, 7.5; riboflavin, 15; pyridoxine, 7.5; nicotinic acid, 87.5; folic acid, 2.5; calcium pantothenate, 2.5; vitamin $B_{12}, 0.025$; ascorbic acid, 250; inositol, 500 ; biotin, 1.25; choline, chloride 500
} 


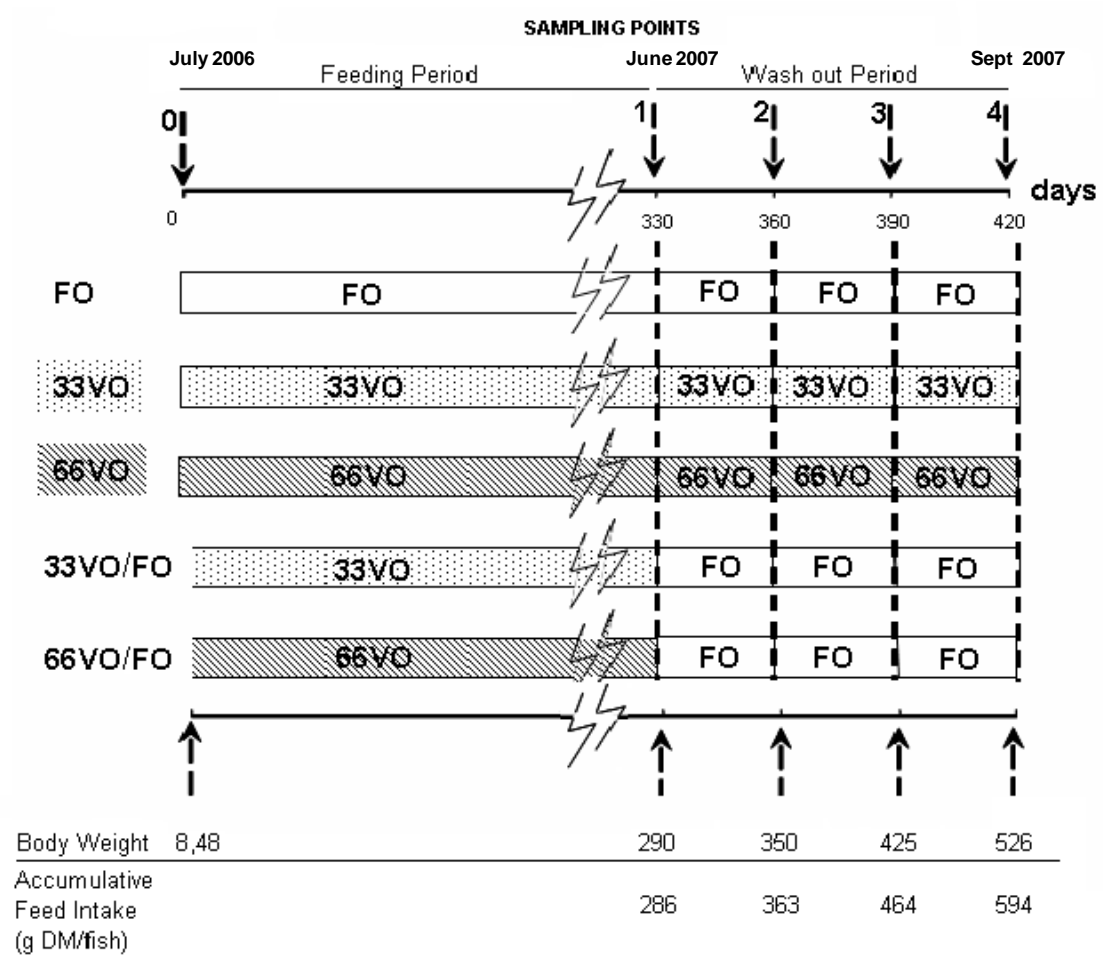

Fig. 1 Schematic representation of the long-term feeding trial over 14 months

treatment were randomly selected to obtain three composite samples of three, three, and two fillets. Fish diets and oils were homogenized and analyzed in triplicate.

Before analysis, samples were thawed at room temperature and were carefully ground (fillets and feeds) using a kitchen grinder (Super JS, Moulinex, France). Approximately 2 g of sample were homogenized with $6 \mathrm{~g}$ of anhydrous sodium sulfate and the blend was spiked with $100 \mu \mathrm{L}$ of surrogate solution $(25 \mathrm{ng} / \mathrm{mL}$ ) Ten milliliters of methanolic solution of $1 \mathrm{M} \mathrm{KOH}$ was added to the mixture and saponified for $3 \mathrm{~h}$ at $80^{\circ} \mathrm{C}$. Then analytes were extracted twice with $8 \mathrm{~mL}$ of $\mathrm{n}$-hexane and the solution filtered through $0.2 \mu \mathrm{m}$ and concentrated under gentle nitrogen stream at $40^{\circ} \mathrm{C}$ to 1 $\mathrm{mL}$ (in the case of oils, extracts were concentrated to $5 \mathrm{~mL}$ ). One milliliter of the extract was passed through the Florisil SPE cartridge previously conditioned with $6 \mathrm{~mL}$ of $\mathrm{n}$-hexane and eluted with $8 \mathrm{~mL}$ dichloromethane:n-hexane (20:80) solution. The eluate was evaporated and redissolved in $0.25 \mathrm{~mL}$ of $n$-hexane. The final extracts obtained after the cleanup procedure were analyzed by means of a triple quadrupole analyzer [details in Nácher-Mestre et al. (2009b)]. Quantification of samples was carried out by means of external calibration curves using the internal standard method. Statistical validation of the method developed was performed by evaluating analytical parameters. The method was applied to the four matrixes studied at different fortification levels offering satisfactory 
recoveries (between $70 \%$ and $120 \%$ ) and precisions $(<30 \%)$ in all cases [more details in NácherMestre et al. (2009b)].

The whole analytical process was carried out in Good Laboratory Practices-certified laboratories of the Research Institute for Pesticides and Water, University Jaume I, Castellón, Spain.

Determination of Fat

The total fat content in the sample extracts was determined gravimetrically, after evaporation at $95^{\circ} \mathrm{C}$ until constant weight.

Data Analysis

The PAH concentrations are expressed as micrograms per kilogram of fresh weight and as micrograms per kilogram of lipid base in fillets. Bioaccumulation factors (BAFs) were calculated as the ratio between lipid-based concentrations of PAHs both in the fish fillets and in the fish feed at each sampling point. Because two different fish feed were used in the 33VO/FO and 66VO/FO groups, calculations of BAFs were made correcting for respective feed intakes. Thus, the arithmetic mean of PAH concentrations in the diet was calculated on the basis of the gram of dry matter ingested per fish, and the concentration of PAHs in each fish feed. BaPEs were calculated for fish fillets using the TEFs proposed by the US EPA (EPA 2000). The concentrations of individual PAHs ( $\mu \mathrm{g} / \mathrm{kg}$ fresh weight) are expressed as equivalents of $\mathrm{BaPy}$, and these values are summed to obtain a BaPEs value. Data for concentrations of PAHs were compared by means of ANOVA I and a posteriori Scheffe's test $(p<0.05)$. All data were log-transformed before statistical analysis to achieve normality. Homoscedasticity of variances was tested by means of Bartlett's test $(p<0.05)$. All of the statistical analyses were conducted using STATGRAPHICS plus for Windows version 4.1 (Statistical Graphics Corporation).

\section{Results and Discussion}

PAHs in Oils and Feeds

The analytical method showed excellent sensitivity and selectivity as a consequence of the use of gas chromatography-coupled tandem mass spectrometry (GC-MS/MS) together with the efficiency of 
the saponification followed by solid-phase extraction clean up. It has allowed analyte quantification at concentrations as low as picograms per gram of fresh weight and micrograms per kilogram of lipid weight in the case of oils, with acceptable precisions (below 30\%) (Nácher-Mestre et al. 2009b).

Concentrations of PAHs present in the oils used in the feeds are shown in Table 2. Up to 14 of the 16 PAHs considered were detected only at trace levels. Both FO and vegetable oils had similar levels and patterns, with individual PAHs concentrations up to $38.2 \mu \mathrm{g} / \mathrm{kg}$ fresh weight and total loads ( $216 \mathrm{PAH}$ ) of $56.7 \mu \mathrm{g} / \mathrm{kg}$ fresh weight in $\mathrm{FO}$ and between 12 and $47 \mu \mathrm{g} / \mathrm{kg}$ fresh weights in vegetable oils. The presence of PAHs in the marine environment has been reported by several authors (Liang et al. 2007; Oros and Ross 2005; Perugini et al. 2007). Vegetable derivatives can accumulate PAHs from different sources such as atmospheric deposition of contaminated dust and particulate matter in the plants and the processing for oil production (Moret and Conte 2000).

The PAH concentrations in the feeds did not correlate with the amounts present in the FO or vegetable oils (VOs) used. We find here that replacement of FO by VOs in the feed did not allow one to minimize the PAHs charge load in complete fish feed. It then appears that the PAHs found in the feed originated from ingredients other than the oils used. The contamination pattern was similar in the different feeds with a predominance of 2-ring PAH naphthalene (up to $215 \mu \mathrm{g} / \mathrm{kg}$ fresh weight) and 3- and 4-ring PAHs, whereas 5- and 6-ring PAHs were less abundant. Naphthalene is the PAH with the lowest K ow and bioconcentration factor (BCF) values. Liang et al. (2007) have reported a similar PAH pattern contamination in fish, with trace concentrations of individual PAHs but naphthalene at concentrations higher than $100 \mu \mathrm{g} / \mathrm{kg}$ fresh weight. In that particular case, this was related to the high accumulation factor biota-sediment calculated for this compound. In our case, the sources and behavior of these compounds are very complex. The different ingredients used in the feeds are processed products from fishery, plant, and industrial sources and the proportions of the different individual PAHs, which could change during the manufacturing process. Even the drying of raw materials by means of hot air could be a potential source of contamination (Moret and Conte 2000). This process is always followed by a considerable increase in PAH content. Moret et al. (2000) reported that oils could have dangerous levels of PAHs for human health due to the drying process. Specifically, BaPy presented an increased concentration in oil samples after drying, ranging from 8.6 to $44.3 \mathrm{ppb}$ (Moret et al. 2000). 
Table 2 Concentration of polycyclic aromatic hydrocarbons (PAHs, $\mu \mathrm{g} / \mathrm{kg}$ ) in the oils used and in the complete feeds

\begin{tabular}{|c|c|c|c|c|c|c|c|c|c|c|c|c|c|c|}
\hline \multirow{2}{*}{$\begin{array}{l}\text { Ingredients } \\
\text { Compound }\end{array}$} & \multicolumn{2}{|l|}{ Fish oil } & \multicolumn{2}{|c|}{ Linseed oil } & \multicolumn{2}{|c|}{ Rapeseed oil } & \multicolumn{2}{|c|}{ Palm oil } & \multicolumn{2}{|l|}{ FO } & \multicolumn{2}{|l|}{$33 \mathrm{VO}$} & \multicolumn{2}{|l|}{$66 \mathrm{VO}$} \\
\hline & Mean & $C V$ & Mean & $C V$ & Mean & $C V$ & Mean & $C V$ & Mean & C.V. & Mean & C.V. & Mean & C.V. \\
\hline Naphthalene & - & & - & & 1.9 & 22 & 0.8 & 24 & 215 & 11 & 242 & 10 & 161 & 9 \\
\hline Acenaphthylene & - & & - & & - & & - & & 0.6 & 16 & 0.6 & 4 & 0.8 & 18 \\
\hline Acenaphthene & 0.3 & 8 & - & & 0.6 & 13 & 0.5 & 15 & 1.7 & 7 & 1.4 & 6 & 1.2 & 8 \\
\hline Fluorene & 4.3 & 5 & 2.6 & 4 & 0.9 & 4 & 0.4 & 8 & 3.8 & 4 & 4 & 10 & 3.5 & 8 \\
\hline Phenanthrene & 38.2 & 2 & 15.2 & 1 & 1.2 & 3 & 1.3 & 3 & 6.1 & 3 & 5.6 & 1 & 5 & 5 \\
\hline Anthracene & - & & - & & 1.6 & 7 & - & & 1.1 & 21 & 1 & 12 & 1.3 & 3 \\
\hline Fluoranthene & 13.3 & 7 & 16.7 & 4 & - & & - & & 2.1 & 3 & 2 & 7 & 2 & 4 \\
\hline Pyrene & 9 & 1 & 11.3 & 1 & - & & - & & 2.1 & 15 & 1.9 & 11 & 1.8 & 10 \\
\hline Benzo(a)Anthracene & - & & - & & 0.9 & 1 & 1.2 & 1 & - & & - & & - & \\
\hline Chrysene & - & & - & & 0.8 & 4 & - & & 0.6 & 6 & 0.8 & 22 & 0.6 & 15 \\
\hline Benzo(b)Fluoranthene & 0.3 & 22 & 0.5 & 4 & 0.4 & 4 & 1.3 & 3 & 0.7 & 13 & 0.6 & 20 & 0.7 & 16 \\
\hline Benzo(k)Fluoranthene & 0.3 & 2 & 0.4 & 5 & 0.4 & 9 & 1.3 & 7 & 0.6 & 25 & 0.6 & 9 & 0.5 & 5 \\
\hline Benzo(a)Pyrene & - & & 0.3 & 8 & 0.7 & 4 & 1.4 & 3 & - & & - & & - & \\
\hline Indeno(1,2,3-cd)Pyrene & - & & - & & 0.7 & 7 & 1.1 & 6 & - & & - & & - & \\
\hline Dibenzo(a.h)Anthracene & - & & - & & 0.9 & 2 & 1.3 & 1 & - & & - & & - & \\
\hline Benzo(g.h.i)Perylene & - & & - & & 0.8 & 8 & 1.2 & 6 & - & & - & & - & \\
\hline इPAH16 & 56.7 & 31 & 47 & 31 & 12 & 2 & 12 & 2 & 234.4 & 44.2 & 260.5 & 39.1 & 178.4 & 34.5 \\
\hline
\end{tabular}

CV: coefficient of variation. Compounds were quantified with CV<30\%. -: non detected. FO: Fish oil diet. 33VO: $33 \%$ vegetable oil diet. 66VO: 66\% vegetable oil diet. 
PAHs in Fish Fed the Different Feeds

Table 3 presents the individual concentrations and 516PAHs in fillets from fish fed the different experimental diets during the study. Initial fish had $46.6 \mu \mathrm{g} / \mathrm{kg}$ fresh weight of $\Sigma 16 \mathrm{PAHs}(1084 \mu \mathrm{g} / \mathrm{kg}$ lipid). After 330 days of feeding with the diets, values descended to $1.1-1.9 \mu \mathrm{g} / \mathrm{kg}$ fresh weight $(14.6-24.4 \mu \mathrm{g} / \mathrm{kg}$ lipid) in the different groups. These low concentrations of PAHs remained at trace levels until the end of the study. Naphthalene was not detected after 11 months of rearing, probably as consequence of its physicochemical characteristics, which could explain the low bioaccumulation ability found here. Similarly, anthracene, benzo[a]anthracene and all 5- and 6-ring PAHs initially present in fish at time 0 were not detected after 330 days of exposure.

Data on BaPEs in the fillets from fish fed the different feeds are also reported in Table 3. BaPE values were below $0.02 \mu \mathrm{g} / \mathrm{kg}$ fresh weight, except for initial fish, which had a value of $9.1 \mu \mathrm{g} / \mathrm{kg}$ fresh weight, which is higher than the maximum level of $2 \mu \mathrm{g} / \mathrm{kg}$ allowed in fish by the Commission Regulation (EC) 1881/2006 (Commission Regulation 2006).

The decrease of PAH concentrations (expressed per unit fresh weight or unit lipid) during the first 11 months suggests the action of a dilution process linked to body mass increase (from 18 to $300 \mathrm{~g}$ ) in the absence of PAH sources other than the low load from diets. This process does not preclude a contaminant biodepuration of PAHs present in initial fish through detoxification metabolic routes. The load of organochlorine pollutants during the same growth study was also monitored (Nácher-Mestre et al. 2009a) and did not reveal any accumulation during the first 11 months of feeding with the different feeds.

As reported in Fig. 2, in spite of the low levels of PAHs found in fish fillets during the study, the I16PAHs concentration appreciably increased after 360 days of exposure in all groups, coinciding with the increase in feed intake and the growth spurt of summer (from 290 to $530 \mathrm{~g}$ in 90 days). These differences were significant at 390 days (Scheffe's test, $p<0.05$ ), especially in groups refed with diet FO and were followed by a plateau by the end of the finishing phase.

The load of POPs, including organochlorine pesticides, polychlorinated byphenyls, PAHs, and polybrominated diphenyl ethers, has also been characterized in the feeds as part of the project. The total load of contaminants (POPs) in diet FO (Nácher-Mestre et al. 2009a) was higher than that of the other feeds. This could lead to a decrease in the efficacy of the PAH metabolism in fish from groups refed FO the last 3 months. On the other hand, the stabilization of the concentrations during the last month of the trial suggests the adaptation of the fish to the uptake levels of pollutants presented the last 3 months of the experiment and the recovery of the ability to biodepurate the PAHs up taken via 
Table 3 Concentrations of PAHs ( $\mu \mathrm{g} / \mathrm{kg}$ fresh weight; $\mathrm{n}=3$ ) in fillets from gilthead sea bream fed the different diets

\begin{tabular}{|c|c|c|c|c|c|c|c|c|c|c|c|c|c|c|c|c|c|c|}
\hline \multicolumn{3}{|l|}{ Diet } & \multicolumn{4}{|l|}{ FO } & \multirow{2}{*}{\multicolumn{2}{|c|}{ T1 }} & \multirow{2}{*}{\multicolumn{2}{|c|}{ T4 }} & \multirow{2}{*}{\multicolumn{2}{|c|}{$\begin{array}{l}\text { 33VOFO } \\
\text { T4 }\end{array}$}} & \multicolumn{4}{|l|}{$66 \mathrm{VO}$} & \multirow{2}{*}{\multicolumn{2}{|c|}{$\begin{array}{l}\text { 66VOFO } \\
\text { T4 }\end{array}$}} \\
\hline exposure & TO & & T1 & & T4 & & & & & & & & T1 & & T4 & & & \\
\hline & Mean & $C V$ & Mean & $C V$ & Mean & $C V$ & Mean & $C V$ & Mean & $C V$ & Mean & $C V$ & Mean & $C V$ & Mean & $C V$ & Mean & $\mathrm{CV}$ \\
\hline Naphthalene & 3.9 & 1 & - & & - & & - & & - & & - & & - & & - & & - & \\
\hline Acenaphthylene & - & & - & & - & & - & & - & & - & & - & & - & & - & \\
\hline Acenaphthene & - & & - & & - & & - & & - & & - & & - & & - & & - & \\
\hline Fluorene & - & & 0.36 & 2 & 0.51 & 8 & 0.32 & 17 & 0.63 & 29 & 0.52 & 28 & 0.22 & 14 & 0.58 & 6 & 0.41 & 5 \\
\hline Phenanthrene & 2.0 & 1 & 0.86 & 26 & 1.83 & 7 & 0.79 & 29 & 2.11 & 27 & 2.40 & 10 & 0.49 & 7 & 2.21 & 18 & 2.13 & 17 \\
\hline Anthracene & 1.0 & 1 & - & & - & & - & & - & & - & & - & & - & & - & \\
\hline Fluoranthene & 3.9 & 1 & 0.28 & 12 & 0.99 & 13 & 0.22 & 16 & 1 & 7 & 1.8 & 22 & 0.18 & 3 & 0.64 & 29 & 1.61 & 11 \\
\hline Pyrene & 4.9 & 1 & 0.4 & 27 & 2.8 & 19 & 0.31 & 19 & 2.07 & 1 & 4.71 & 27 & 0.25 & 9 & 1.35 & 29 & 4.21 & 12 \\
\hline Benzo(a)Anthracene & 4.9 & 1 & - & & - & & - & & 0.09 & 13 & - & & - & & 0.14 & 2 & 0.15 & 13 \\
\hline Chrysene & 6.9 & 1 & - & & 0.14 & 13 & - & & 0.17 & 14 & 0.16 & 8 & - & & 0.16 & 4 & 0.18 & 20 \\
\hline Benzo(b)Fluoranthene & 5.9 & 1 & - & & - & & - & & - & & - & & - & & - & & - & \\
\hline Benzo(k)Fluoranthene & 5.9 & 1 & - & & - & & - & & - & & - & & - & & - & & - & \\
\hline Benzo(a)Pyrene & 3.9 & 1 & - & & - & & - & & - & & - & & - & & - & & - & \\
\hline Indeno(1,2,3-cd)Pyrene & - & & - & & - & & - & & - & & - & & - & & - & & - & \\
\hline Dibenzo(a.h)Anthracene & - & & - & & - & & - & & - & & - & & - & & - & & - & \\
\hline Benzo(g.h.i)Perylene & 3.4 & 1 & - & & - & & - & & - & & - & & - & & - & & - & \\
\hline $\begin{array}{lll}\text { SPAH16 } & (\mu \mathrm{g} / \mathrm{kg} & \text { resh }\end{array}$ & 46.6 & 3 & 1.9 & 20 & 6.3 & 7 & 1.6 & 19 & 6.06 & 7 & 9.6 & 26 & 1.1 & 12 & 5.1 & 14 & 8.7 & 6 \\
\hline$\Sigma$ PAH16 $(\mu \mathrm{g} / \mathrm{kg}$ lipid & 1084 & 36 & 24.4 & 9 & 68.2 & 10 & 21.6 & 9 & 60.6 & 9 & 85.8 & 7 & 14.6 & 3 & 50.8 & 9 & 79.7 & 9 \\
\hline BaPEs $(\mu \mathrm{g} / \mathrm{kg}$ fresh & 9.1 & 2 & 0.002 & 10 & 0.007 & 15 & 0.002 & 13 & 0.002 & 19 & 0.013 & 16 & 0.001 & 6 & 0.006 & 15 & 0.010 & 21 \\
\hline
\end{tabular}




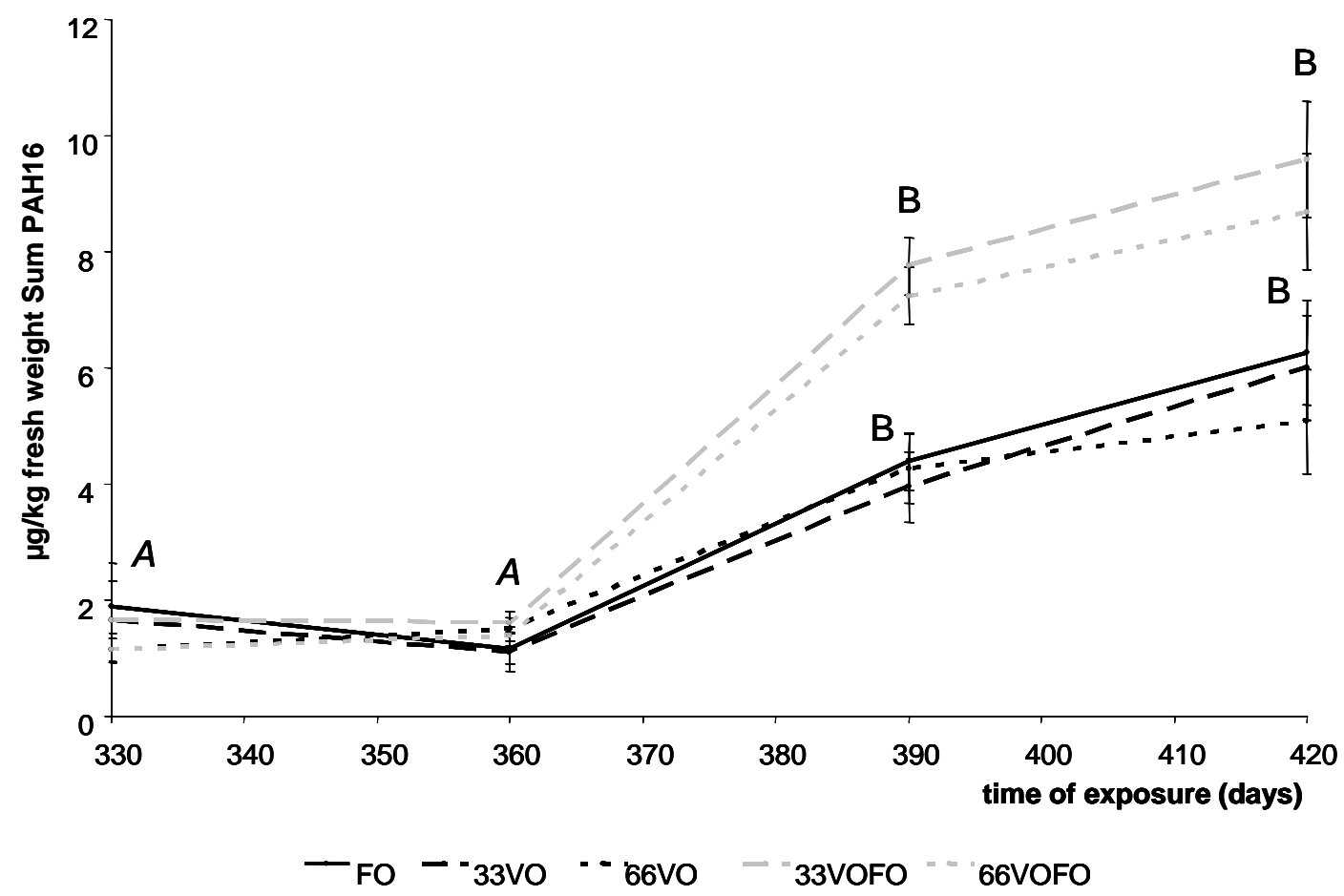

Fig. 2 Concentration of $\sum_{16} \mathrm{PAH}$ in fillets of fish fed different experimental diets with varying levels of fish oil substitution, during the feeding trial. Letters denote significant differences among sampling times for all groups; Scheffe's test; $p<0.05$

diet. The extent to which this biodepuration process coexists with the above-mentioned dilution mechanism and the relative efficiency of both, especially foreseen in shorter periods of higher toxicant intake, like the finishing phase, remains to be ascertained.

Although it should be kept in mind that the concentrations present in fish are at the trace level, the increase of the PAH content at T4 could be explained in light of the increase of feed intake (Fig. 1) during the finishing phase and the reaching of a PAH intake level higher than the detoxification route capability.

In comparison with concentrations reported in the literature regarding seafood samples (Fontcuberta et al. 2006; Llobet et al. 2006; Saeed et al. 1995), ZtPHHs values determined in gilthead sea bream as found here after 330 days of culture were low ( 2 $\mu \mathrm{g} / \mathrm{kg}$ ). Although the concentration increased again during the finishing phase, as we have indicated earlier, it remained low, below $10 \mu \mathrm{g} / \mathrm{kg}$ in all groups, and similar to those found in fish from unpolluted areas. DouAbdul et al. (1997) indicated concentrations from $<0.5$ to $148 \mu \mathrm{g} / \mathrm{kg}$ fresh weight in fish fillets from 
unpolluted areas. Bordajandi et al. (2004) reported levels between 8.2 and $71.4 \mu \mathrm{g} / \mathrm{kg}$ fresh weight in marine food samples from Spain, whereas Loufty et al. (2007) found levels in market fish samples from Egypt ranging from 0.78 to 19.70 , similar to those observed in gilthead sea bream in this study and very low in comparison to polluted areas.

As reported in Table 4, individual PAHs found in fish fillets show variable BAF values. Phenanthrene, fluoranthene, and pyrene showed BAFs over 1 in almost all groups of fish. Phenanthrene, fluoranthene, and pyrene are bioaccumulated probably as a consequence of their high K ow (Table 4) because possible sources of these compounds other than diet, like combustions or petroleum, can be discarded. Nevertheless, chrysene had BAF values below 1 in spite of its higher $\mathrm{K}$ ow, which could be interpreted in terms of a more efficient degradation or depuration of this compound. On the basis of data obtained here, the different BAF values found for the different individual PAHs can be attributed to the variety of structures and physicochemical properties of the different components of the family.

Table 4 Bioaccumulation factors (BAF) for the polycyclic aromatic hydrocarbons (PAHs) detected after 420 days of the growth trial with the different diets (from lipid based concentrations in fish fillets and diets, $n=3$ )

\begin{tabular}{|c|c|c|c|c|c|c|c|c|c|c|c|}
\hline \multirow{2}{*}{$\begin{array}{l}\text { Diet } \\
\text { Compound }\end{array}$} & \multicolumn{2}{|l|}{ FO } & \multicolumn{2}{|c|}{$33 \mathrm{VO}$} & \multicolumn{2}{|c|}{ 33VOFO } & \multicolumn{2}{|c|}{$66 \mathrm{VO}$} & \multicolumn{2}{|c|}{ 66VOFO } & \multirow[t]{2}{*}{ Kow } \\
\hline & $B A F$ & $C V$ & $B A F$ & $C V$ & $B A F$ & $C V$ & $B A F$ & $C V$ & $B A F$ & $C V$ & \\
\hline Fluorene & 0.29 & 8 & 0.32 & 29 & 1.10 & 6 & 0.26 & 28 & 0.98 & 5 & 4.18 \\
\hline Phenanthrene & 0.65 & 7 & 0.75 & 27 & 2.45 & 18 & 1.21 & 10 & 1.63 & 17 & 4.57 \\
\hline Fluoranthene & 1.02 & 13 & 1.00 & 7 & 2.28 & 29 & 1.80 & 22 & 2.42 & 11 & 5.22 \\
\hline Pyrene & 2.90 & 19 & 2.18 & 1 & 4.05 & 29 & 6.01 & 27 & 3.60 & 12 & 5.18 \\
\hline Chrysene & 0.51 & 13 & 0.43 & 14 & 0.52 & 8 & 0.49 & 4 & 0.91 & 20 & 5.86 \\
\hline
\end{tabular}

Sources

The study of three PAH isomer ratios-anthracene/anthracene + phenanthrene (An/178), benz[a]anthracene/benz[a]anthracene + chrysene $(\mathrm{BaA} / 228)$, and fluoranthene/fluoranthene + 
pyrene $[\mathrm{FI} /(\mathrm{FI}+\mathrm{Py})$ - was applied to identify the possible major sources of these contaminants in the different matrixes considered in this work (Table 5). These PAH ratios can be used as indicators of the different formation processes of the PAH contamination and of the possible sources of contamination in sediments (Yunker et al. 2002). FO and VOs have An/178 ratios below 0.1, which suggest unburned petroleum as one of the sources of the contamination present in these products. These An/178 ratios determined in the oils are similar to those found by Yunker et al. (2002) in sediments from remote or light-urban areas. The FO used in this research was from South American origin, which could explain the presence of PAHs from unburned petroleum. $\mathrm{Fl} /(\mathrm{FI}+\mathrm{Py})$ and $\mathrm{BaA} / 228$ ratios indicate nonpetroleum combustion sources of the PAHs found in the samples, supporting the idea of PAH contamination from light-urbanized areas.

Table $5 \mathrm{PAH}$ isomer ratios (mean $\pm \mathrm{SD}, \mathrm{n}=6$ ) in oils, diets, and fish fed the different diets

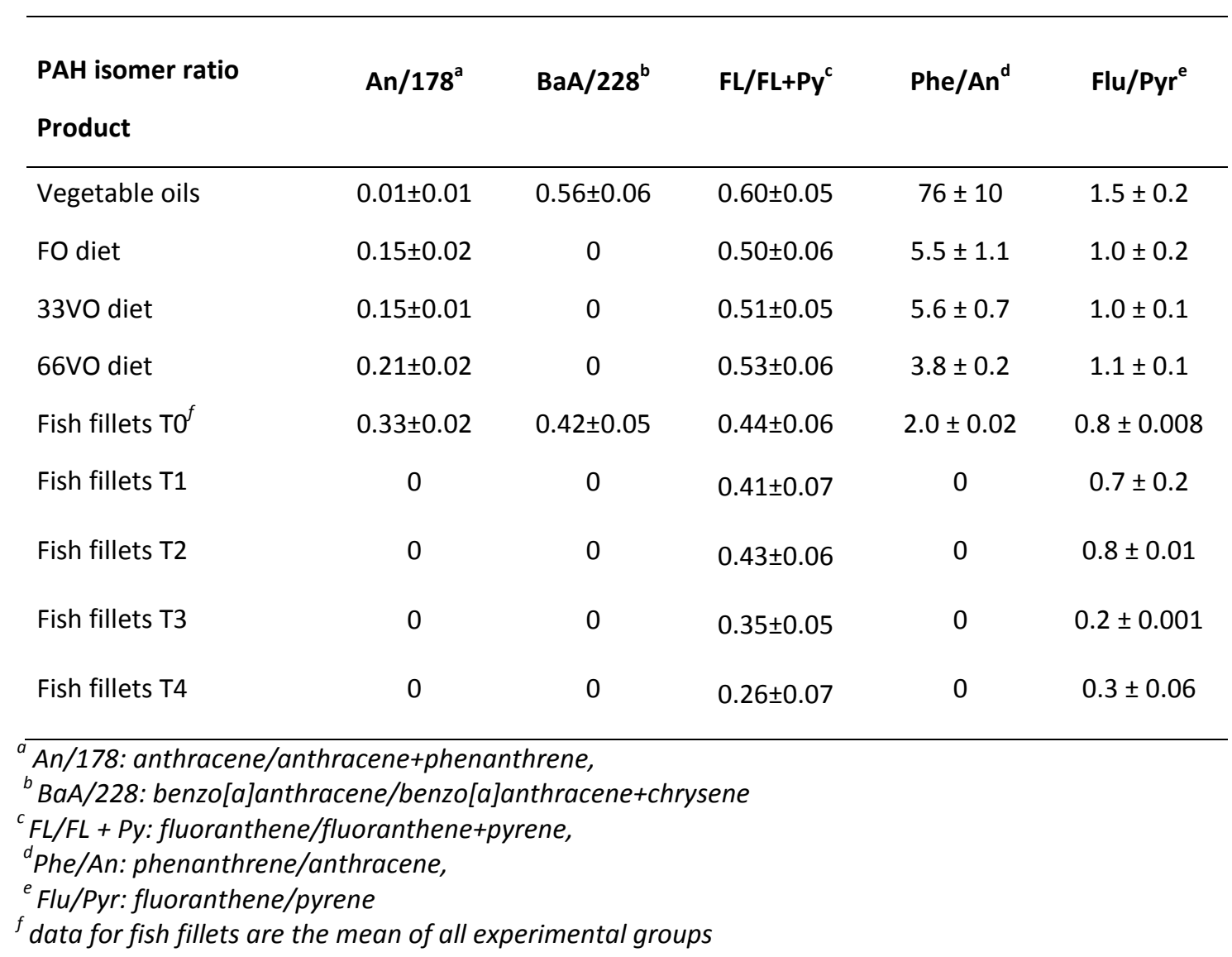

The feeds manufactured with the above-studied ingredients showed higher An/178 values, probably as a consequence of the manufacture process itself that could provoke degradations and 
contaminations of the different individual PAHs. However, it is interesting to note that benzo[a]anthracene was not detected in the feed, possibly due to the degradation process during manufacture, as this PAH is one of the less stable (Yunker et al. 2002). The $\mathrm{Fl} /(\mathrm{FI}+\mathrm{Py}$ ) ratios found in the feeds are similar to those of the oils used: below 0.5.

Initial fish showed values for $\mathrm{An} / 178, \mathrm{BaA} / 228$, and $\mathrm{Fl} /(\mathrm{FI}+\mathrm{Py})$ of $0.333,0.415,0443$, respectively. These values indicate both petroleum combustion and other combustions as sources of the PAHs in sediments (Yunker et al. 2002) and bivalves (Oros and Ross 2005), accumulated prior to the beginning of the present study. The $A n / 178$ and $B a A / 228$ ratios decreased to 0 after 11 months of culture, whereas $\mathrm{Fl} /(\mathrm{FI}+\mathrm{Py})$ values decreased continuously during the whole growth period, suggesting a decrease of PAH exposure during the experimental period.

\section{Conclusions}

The levels of PAHs found in fish fillets grown with different diets over a full production cycle were very low and similar to those reported in foods from unpolluted marine areas. These low levels correspond to low levels of PAHs found in the diets and the lack of other potential sources of contamination in the rearing facilities over the experimental period. These conditions together with dilution and biodepuration mechanisms result in a net decrease of total PAH loads present in experimental fish at the start of the experiment and, thus, in the production of market size fish of good quality for human consumption.

Acknowledgment This study was carried out with the financial support of the European Union Project: Sustainable Aquafeeds to Maximise the Health Benefits of Farmed Fish for Consumers (AQUAMAX), contract number 016249-2.

\section{References}

Bell JG, McGhee F, Dick JR, Tocher DR (2005) Dioxin and dioxin-like polychlorinated biphenyls (PCBs) in Scottish farmed salmon (Salmo salar): effects of replacement of dietary marine fish oil with vegetable oils. Aquaculture 243:305-314

Benedito-Palos L, Navarro JC, Bermejo-Nogales A, Saera-Vila A, Kaushik S, Pérez-Sánchez J (2009) The time course of fish oil wash-out follows a simple dilution model in gilthead sea bream (Sparus aurata L.) fed graded levels of vegetable oils. Aquaculture 288:98-105 
Berntssen MHG, Lundebye AK, Torstennsen BE (2005) Reducing the levels of dioxins and dioxin-like PCBs in farmed Atlantic salmon by substitution of fish oil with vegetable oil in the feed. Aquacult Nutr 11:219-231

Bethune C, Seierstad SL, Seljeflot I, Johansen O, Arnesen H, Meltzer HM, Rosenlund G, Froyland L, Lundebye AK (2006) Dietary intake of differentially fed salmon: a preliminary study on contaminants. Eur J Clin Invest 36:193-201

Bordajandi LR, Gómez G, Abad E, Rivera J, Del Mar Fernandez-Baston M, Blasco J, González MJ (2004) Survey of persistent organochlorine contaminants (PCBs, PCDD/Fs, and PAHs), heavy metals $(\mathrm{Cu}, \mathrm{Cd}, \mathrm{Zn}, \mathrm{Pb}$, and $\mathrm{Hg})$, and arsenic in food samples from Huelva (Spain): levels and health implications. J Agric Food Chem 52:992-1001

Bordajandi LR, Martín I, Abad E, Rivera J, Gonzalez MJ (2006) Organochlorine compounds (PCBs, PCDDs and PCDFs) in sea fish and seafood from the Spanish Atlantic Southwest Coast. Chemosphere 64:1450-1457

Bories G (ed) (1988) Tossicologia e sicurezza degli alimenti. Tecniche Nuove, Milan, p 359

Commission Regulation (2006) Commission Regulation (EC) No 1881/2006 of 19 December 2006 setting maximum levels for certain contaminants in foodstuffs. Available from (eurlex.europa.eu/LexUriServ/site/en/oj/2006/I_364/I_36420061220en00050024.pdf)

Cortazar E, Bartolomé L, Arrasate S, Usobiaga A, Raposo JC, Zuloaga O, Etxebarria N (2008) Distribution and bioaccumulation of PAHs in the UNESCO protected natural reserve of Urdaibai, Bay of Biscay. Chemosphere 72:1467-1474

Directiva 2000/60/CE del Parlamento Europeo y del Consejo, de 23 de octubre de 2000, por la que se establece un marco comunitario de actuación en el ámbito de la política de aguas.

DouAbdul AAZ, Heba HMA, Farred KH (1997) Polynuclear aromatic hydrocarbons (PAHs) in fish from the Red Sea Coast of Yemen. Hydrobiologia 352:251-262

EPA (1987) Quality criteria for water. EPA 440/5-86-001. US Environmental Protection Agency, Washington DC

EPA (1993) Provisional guidance for quantitative risk assessment of polycyclic aromatic hydrocarbons. EPA 600/R-93/089. US Environmental Protection Agency, Washington DC

EPA (2000) Guidance for assessing chemical contaminant data for use in fish advisories. EPA. 823-B00-008. US Environmental Protection Agency, Washington DC

Easton MDL, Luszniak D, Von der Geest E (2002) Preliminary examination of contaminant loadings in farmed salmon, wild salmon and commercial salmon feed. Chemosphere 46:1053-1074 
Ferreira M, Moradas-Ferreira P, Reis-Henriques MA (2006) The effect of long-term depuration on phase I and phase II biotransformation in mullets (Mugil cephalus) chronically exposed to pollutants in River Douro Estuary, Portugal. Marine Environ Res 61:326-338

Fontcuberta M, Arqués JF, Martínez M, Suárez A, Villalbí JR, Centrich F, Serrahima E, Duran J, Casas C (2006) Polycyclic aromatic hydrocarbons in food samples collected in Barcelona, Spain. J Food Prot 69:2024-2028

Hellou J, Haya K, Steller S, Burridge L (2005) Presence and distribution of PAHs, PCBs and DDE in feed and sediments under salmon aquaculture cages in the Bay of Fundy, New Brunswick, Canada. Aquat Conserv 15:349-365

Hendricks JD, Meyeres TR, Shelton DW, Casteel JL, Bailey GS (1985) Hepatocarcinogenicity of benzo(a)pyrene to rainbow trout by dietary exposure and intraperitoneal injection. J Natl Cancer Inst 74:839-851

Hites RA, Foran JA, Carpenter DO, Hamilton MC, Knuth BA, Schwager SJ (2004) Assessment of organic contaminants in farmed salmon. Science 303:226-229

IARC, (1987). IARC monographs on the evaluation of carcinogenic risks to humans, supplement 7. Overall evaluations of carcinogenicity: an updating of IARC monographs, vol 1-42., Vol. International Agency for Research on Cancer, Lyon.

Jacobs MN, Santillo D, Johnston PA, Wyatt CL, French MC (1998) Organochlorine residues in fish oil dietary supplements: comparison with industrial grade oils. Chemosphere 37:1709-1721

Kennedy CJ, Higgs D, Tierney K (2004) influence of diet and ration level on benzo[a]pyrene metabolism and excretion in rainbow trout (Oncorhyncus mykiss). Arch Environ Contam Toxicol 47:379-386

Latimer JS, Zheng J (2003) Sources, transport and fate of PAHs in the marine environment. In: Douben PET (ed) PAH: an ecotoxicological perspective. Wiley, Chichester, UK, pp 9-33

Law RJ, Kelly C, Baker K, Jones J, McIntosh AD, Moffat CF (2002) Toxic equivalency factors for PAH and their applicability in shellfish pollution monitoring studies. J Environ Monit 4:383-388

Liang Y, Tse MF, Young L, Wong MH (2007) Distribution patterns of polycyclic aromatic hydrocarbons (PAHs) in the sediments and fish at Mai Po Marshes Nature Reserve, Hong Kong. Water Res 41:1303-1311

Llobet JM, Falcó G, Bocio A, Domingo JL (2006) Exposure to polycyclic aromatic hydrocarbons through consumption of edible marine species in Catalonia, Spain. J Food Prot 69:2493-2499 
Loufty N, Fuerhacker M, Tundo P, Raccanelli S, Ahmed MT (2007) Monitoring of polychlorinated dibenzo-p-dioxins and dibenzofurans, dioxin-like PCBs and polycyclic aromatic hydrocarbons in food and feed samples from Ismailia city, Egypt. Chemosphere 66:1962-1970

Martí-Cid R, Bocio A, Llobet JM, Domingo JL (2007) Intake of chemical contaminants through fish and seafood consumption by children of Catalonia, Spain: health risks. Food Chem Toxicol 45:19681974

Martí-Cid R, Llobet JM, Castell V, Domingo JL (2008) Evolution of the dietary exposure to polycyclic aromatic hydrocarbons in Catalonia, Spain. Food Chem Toxicol 46:3163-3171

Martin-Skilton R, Saborido-Rey F, Porte C (2008) Endocrine alteration and other biochemical responses in juvenile trubot exposed to the Prestige fuel oil. Sci Total Environ 404:68-76

Maule AG, Gannam AL, Davis JW (2007) Chemical contaminants in fish feeds used in federal salmonid hatcheries in the USA. Chemosphere 67:1308-1315

Moret S, Conte LS (2000) Polycyclic aromatic hydrocarbons in edible fats and oils: occurrence and analytical methods. J Chromatogr A 882:245-253

Moret S, Dudine A, Conte LS (2000) Processing effects on the polyaromatic hydrocarbon content of grapeseed oil. J Am Oil Chem Soc 77:1289-1292

Nácher-Mestre J, Serrano R, Benedito-Palos L, Navarro JC, Lopez FJ, Pérez-Sanchez J (2009a) Effects of fish oil replacement and re-feeding on the bioaccumulation of organochlorine compounds in gilthead sea bream (Sparus aurata L.) of market size. Chemosphere 76:811-817

Nácher-Mestre J, Serrano R, Portolés T, Hernández F, Benedito-Palos L, Pérez-Sanchez J (2009b) A reliable analytical approach based on gas chromatography coupled to triple quadrupole and time of flight analyzers for the determination and confirmation of polycyclic aromatic hydrocarbons in complex matrices from aquaculture activities. Rapid Commun Mass Spectrom 23:2075-2086

Nisbet IC, LaGoy PK (1992) Toxic equivalency factors (TEFs) for polycyclic aromatic hydrocarbons (PAHs). Regul Toxicol Pharm 16:290-300

Oros DR, Ross JRM (2005) Polycyclic aromatic hydrocarbons in bivalves from the San Francisco estuary: spatial distributions, temporal trends, and sources (1993-2001). Marine Environ Res $60: 466-488$

Oterhals Å, Nygård E (2008) Reduction of persistent organic pollutants in fishmeal: a feasibility study. J Agric Food Chem 56:2012-2020 
Oterhals Å, Solvang M, Nortvedt R, Berntssen MHG (2007) Optimization of activated carbon-based decontamination of fish oil by response surface methodology. Eur J Lipid Sci Technol 109:691705

Perugini M, Visciano P, Giammarino A, Manera M, Di Nardo W, Amorena M (2007) Polycyclic aromatic hydrocarbons in marine organisms from the Adriatic Sea, Italy. Chemosphere 66:1904-1910

Pitarch E, Medina C, Portolés T, Lopéz FJ, Hernández F (2007) Determination of priority organic micro-pollutants in water by gas chromatography coupled to triple quadrupole mass spectrometry. Anal Chim Acta 583:246-258

Saeed T, Al-Yakoob S, Al-Hashash H, Al-Bahloul M (1995) Preliminary exposure assessment for Kuwaiti consumers to polycyclic aromatic hydrocarbons in seafood. Environ Int 21:255-263

Santerre CR, Ingram R, Lewis GW, Davis JT, Lane LG, Grodner RM, Wei Cl, Bush PB, Xu DH, Shelton J, Alley EG, Hinshaw JM (2000) Organochlorines, organophosphates, and pyrethroids in channel catfish, rainbow trout, and red swamp crayfish from aquaculture facilities. J Food Sci 65:231235

Schultz M, Schultz J (1982) Induction of hepatic tumors with 7, 12-dimethyl-benzantracene in two species of viviparous fishes (genus Poecillopsis). Environ Res 27:337-351

Serrano R, Barreda M, Blanes MA (2008a) Investigating the presence of organochlorine pesticides and polychlorinated biphenyls in wild and farmed gilthead sea bream (Sparus aurata) from the Western Mediterranean Sea. Marine Pollut Bull 56:963-972

Serrano R, Blanes MA, López FJ (2008b) Biomagnification of organochlorine pollutants in farmed and wild gilthead sea bream (Sparus aurata) and stable isotope characterization of the trophic chains. Sci Total Environ 389:340-349

Stegeman JJ, Lech JJ (1991) Cytochrome P-450 monooxygenase systems in aquatic species: carcinogen metabolism and biomarkers for carcinogen and pollutant exposure. Environ Health Perspect 90:101-109

Yunker MB, Macdonald RW, Vingarzan R, Mitchell RH, Goyette D, Sylvestre S (2002) PAHs in the Fraser river basin: a critical appraisal of PAH ratios as indicators of PAH source and composition. Org Geochem 33:489-515 
